\title{
O sentido e o som: três teorias da tradução de poesia em diálogo
}

\author{
Beatriz Cabral Bastos
}

\begin{abstract}
This article presents and discusses different theories of poetry translation by the authors Henri Meschonnic, Haroldo de Campos and Paulo Henriques Britto. Though quite different from each other, all the authors seem to somehow respond to Susan Sontag's famous 1964 essay, "Against Interpretation". Our belief is that the "hands on" work involved in translating poetry leads to a special attention not only to the meaning of the poem, but to everything that concerns its materiality and form. In addition to explaining and giving examples of the works of these three theorists, we intend to show how the theory of poetry translation might be an interesting space of reflection not just for translators but also language and literary theorists in general. By bringing these theories together, we also intend to contribute to the delineation of theories of poetry translation within the larger field of Translation Studies.
\end{abstract}

Keywords: theory of translation; poetry; materiality; Henri Meschonnic; Haroldo de Campos; Paulo Henriques Britto.

Resumo: Neste artigo são apresentadas e colocadas em diálogo as teorias da tradução de poesia de Henri Meschonnic, Haroldo de Campos e Paulo Henriques Britto. Embora bastante diferentes entre si, são teorias que parecem de algum modo responder à tarefa colocada por Susan Sontag em seu famoso ensaio de 1964, "Contra a interpretação". A nossa aposta é a de que corpo a corpo do trabalho de tradução conduz a uma atenção especial não apenas ao sentido do poema, mas a tudo que diz respeito a sua materialidade, a sua forma. Além de aprofundar e trazer exemplos dos trabalhos desses três teóricos, demonstra-se como a teoria sobre a tradução de poesia pode ser um interessante espaço de reflexão não apenas para os tradutores, mas também, de modo amplo, para os teóricos da linguagem e da literatura. Ao reunir estes teóricos, pretende-se também contribuir para um mapeamento das teorias de tradução de poesia, dentro do campo mais amplo dos Estudos da Tradução.

Palavras-chave: teoria da tradução; poesia; materialidade; Henri Meschonnic; Haroldo de Campos; Paulo Henriques Britto.

\footnotetext{
* Doutoranda do Programa de Pós-gradução em Literatura, Cultura e Contemporaneidade da PUC-Rio. Email: bebatriz@gmail.com.
} 
Bastos, B. C. - O sentido e o som: três teorias da tradução de poesia em diálogo

\section{Introdução}

Em "Contra a interpretação", de 1964, Susan Sontag critica o que via como um excesso interpretativo da crítica, que ela compara ao bombardeamento dos sentidos dentro do ambiente urbano, e acrescenta: "a consequência é uma perda constante da acuidade de nossa experiência sensorial" (SONTAG 1987: 23). Propõe então uma crítica de arte que possa fornecer uma "descrição realmente cuidadosa, aguda, carinhosa da aparência da obra de arte" (Ibid.: 22). Uma crítica que possa revelar a superfície sensual da arte sem conspurcá-la.

O que importa agora é recuperarmos nossos sentidos. Devemos aprender a ver mais, ouvir mais, sentir mais. Nossa tarefa não é descobrir o maior conteúdo possível numa obra de arte, muito menos extrair de uma obra de arte um conteúdo maior do que já possui. Nossa tarefa é reduzir o conteúdo para que possamos ver a coisa em si. Agora, o objetivo de todo comentário sobre arte deveria visar tornar as obras de arte - e, por analogia, nossa experiência - mais e não menos reais para nós. A função da crítica deveria ser mostrar como é que é, até mesmo o que é que é, e não mostrar o que significa (SONTAG 1987: 23).

"Em vez de uma hermenêutica, precisamos de uma erótica da arte", conclui SONTAG (Ibid.: 23). A nosso ver, o tradutor de poesia encontra-se em uma posição de algum modo privilegiada para efetuar esta tarefa crítica de ver mais, sentir mais e ouvir mais, pois a poesia - definida por Paul Valery como uma hesitação prolongada entre o sentido e o som - talvez de modo mais marcante que outros gêneros textuais, nos leve a refletir sobre tudo aquilo no texto que está para além dos significados e da interpretação. 0 tradutor, se deseja transpor para uma nova língua aquilo que faz um poema, precisa, além de se preocupar com seu aspecto semântico, voltar sua atenção 
Bastos, B. C. - 0 sentido e o som: três teorias da tradução de poesia em diálogo

para a materialidade do poema, isto é, também voltar sua atenção à forma, ao seu aspecto visual e sonoro, ao seu ritmo.

Neste artigo, apresentaremos e colocaremos em diálogo o trabalho de diferentes teóricos da tradução que voltaram sua atenção especialmente à tradução de poesia. São teorias que buscam, cada uma ao seu modo, dar conta não apenas do aspecto interpretativo do poema, mas que valorizam também isso que estamos chamando de materialidade do texto poético, os seus aspectos não exatamente semânticos. Primeiramente, traremos a "poética do traduzir" de Henri Meschonnic, que, ao se dedicar à tradução da Bíblia, elaborou, a partir disso, uma sofisticada teorização que dá importância primordial à questão do ritmo. Em seguida, retomamos alguns pensamentos de Haroldo de Campos sobre o conceito de "transcriação" e o seu enfoque na tradução da forma. Por último, traremos também algumas reflexões de Paulo Henriques Britto, cuja busca por certa objetividade na avaliação de traduções poéticas proporciona, a nosso ver, ricas ferramentas de análise. Ao reunirmos estes teóricos, todos eles também poetas e tradutores, pretendemos contribuir para um mapeamento das teorias dedicadas à tradução de poesia, dentro do campo mais amplo dos Estudos da Tradução.

\section{Poétique du traduire - Poética do traduzir}

Henri Meschonnic explica que a expressão "poética do traduzir" se refere à poética de uma atividade e não apenas a um produto pronto. Para ele, a teoria é um acompanhamento reflexivo de uma experiência. Seu objetivo é delinear sua própria poética sobre o ato de traduzir, e seus produtos, a tradução. A tradução, diz Meschonnic, pode ter um papel único como reveladora do pensamento da linguagem e da literatura, e esta 
Bastos, B. C. - O sentido e o som: três teorias da tradução de poesia em diálogo

possibilidade foi subestimada devido à condição auxiliar que the impôs a tradição. Ao subverter esta tradição que sempre viu a tradução como algo secundário e trazer a poesia para o centro de sua teoria da linguagem, Meschonnic cria algo que não é apenas uma estratégia de tradução de poesia, mas uma potente poética-crítica de caráter mais amplo.

Os textos de Henri Meschonnic, de modo geral, deixam transparecer certa irritação, parecendo verdadeiros textos de luta ${ }^{1}$. Sua batalha crítica é contra diversas tradições de pensamento no campo da linguagem e da literatura, como se dissesse: "apesar de vocês, a poesia resiste!". Por isso, marca seu lugar como defensor do ritmo, dizendo que só através de uma escuta atenta ao ritmo do texto podemos nos livrar tanto do que ele denomina o "império dos significados" - a tradição hermenêutica, focada na interpretação - como dos excessos da tradição formalista, que separa a linguagem poética da linguagem cotidiana. Afirma também que é preciso reaprender uma escuta do ritmo, uma vez que a dicotomia estrutural inerente à noção de signo (forma/ sentido - significante/ significado), ele diz, teria nos deixado surdos. Para Meschonnic, é a própria poesia que faz essa crítica ao signo, pois, apesar de tentarem sufocá-la e domesticá-la, ela estaria carregada de "vida".

\begin{abstract}
A poesia transforma tudo em vida. Ela é esta forma de vida que transforma tudo em linguagem. Ela só nos acontece se a própria linguagem se torna uma forma de vida. Por isso ela é tão inquieta. Pois ela não cessa de trabalhar sobre nós. De ser o sonho daquilo que somos o sono. Uma escuta, um despertar que nos atravessa, um ritmo que nos conhece e que nós não conhecemos ${ }^{2}$ (MESCHONNIC 1989: 247).
\end{abstract}

\footnotetext{
${ }^{1}$ Gabriella Bedetti também aponta para essa característica de Meschonnic: Um expoente agressivo, ele ataca a imobilidade por todos os lados. (BEDETTI 1992: 433, tradução da autora).

${ }^{2}$ Todas as citações de Meschonnic são traduções feitas exclusivamente para este artigo, pela autora. Original: La poésie fait vie de tout. Elle est cette forme de vie que fait langage de tout. Elle ne nous arrive que si le langage même est devenu uns forme de vie. C'est pourquoi elle est si peu paisible. Car elle ne cesse de nous travailler. D'être le rêve dont nous sommes
} 
Bastos, B. C. - O sentido e o som: três teorias da tradução de poesia em diálogo

A poesia teria mais a ver com o tempo por se encontrar mais no ritmo do que nas palavras do poema. E o ritmo, mais do que o som ou uma alternância entre sílabas fortes e fracas, é o modo de significar, é a semântica prosódica e rítmica, e não deve ser confundido com o significado. Para ele, a teoria do signo tentaria esconder e ignorar a poesia, mas ela "não cessa de reaparecer", pois pertence à vida, ao "contínuo irracional" (1989: 249). "Os signos [signes] não compreendem os cisnes [cygnes]" (1989: 250). A noção de signo teria nos deixado surdos ao discurso como atividade do sujeito. Por isso, afirma, é preciso reaprender um modo de escuta, é preciso ouvir o suj eito, e o suj eito está no ritmo.

No livro Poétique du traduire, os principais alvos do autor enquanto modos de se pensar a tradução são as teorias da linguagem do "tradutor profissional" e a teoria da linguagem da hermenêutica. Para ele, é impossível desvencilhar a teoria da linguagem do tradutor de sua prática tradutória e, estando o tradutor amparado por essas teorias da linguagem, não terá condições de fazer boas traduções.

Meschonnic dirá que o ponto de vista mais comumente adotado pelos especialistas e profissionais da tradução é o da "estilística comparada" (1999: 14), cuja principal preocupação seria a de buscar a fidelidade e 0 apagamento do tradutor diante do texto, fazendo esquecer que se trata de uma tradução. Este ponto de vista se realizaria através de supostas noções de bom senso, como língua de saída, língua de chegada, equivalência, fidelidade, transparência, apagamento e modéstia do tradutor. 0 acompanhamento tradicional destas noções seria a separação entre "sentido" e "estilo" e entre "sentido" e "forma" (p. 21). Nestas noções, estaria imbuída a ideia de tradução como interpretação, sendo que a boa tradução não passa apenas pela interpretação:

le sommeil. Une écoute, un éveil qui nous traverse, le rythme qui nous connaît et que nous ne connaissons pas. 
Bastos, B. C. - O sentido e o som: três teorias da tradução de poesia em diálogo

\begin{abstract}
Paradoxalmente, uma boa tradução não deve ser pensada como interpretação. Porque a interpretação é da ordem do sentido, e do signo. Do descontínuo. Radicalmente diferente do texto, que faz aquilo que diz. O texto conduz e comporta. A interpretação é apenas conduzida. A boa tradução deve fazer, e não apenas dizer. Ela deve, como o texto, comportar e conduzir ${ }^{3}$ (MESCHONNIC 1999: 22).
\end{abstract}

O ponto fraco da visão "profissional" da tradução é que ela refletiria apenas um pensamento da língua, não um pensamento da literatura - a especificidade da literatura Ihe escapa. Segundo Meschonnic, no mundo literário, o ponto de vista hermenêutico e fenomenológico da tradução seria o mais difundido. A fenomenologia, ao identificar a tradução à compreensão dentro de uma mesma língua, ampliou uma concepção de tradução da hermenêutica alemã do começo do século XX (p. 15). A paráfrase e a inserção de glosas nas traduções, diz o autor, decorrem desta concepção de tradução. Meschonnic reconhece uma dimensão hermenêutica inerente a toda tradução, mas defende que fazer simplesmente uma hermenêutica da tradução é permanecer no dualismo que desassocia significantes de significados, pois o texto é colocado na compreensão, no intérprete, no "querer dizer" fenomenológico (p. 72). Ocorreria aqui uma dupla hegemonia: do sentido e do intérprete. E se a tradução for vista como uma atividade apenas interpretativa, a poesia se torna mesmo o intraduzível, o inalcançável, não se podendo ouvir a sua voz: "A hermenêutica aplicada à tradução transporta apenas um cadáver. Ou melhor, um espírito. O corpo fica na outra margem. E o espírito sozinho não tem voz" ${ }^{4}$ (p. 152).

\footnotetext{
3 Original: Paradoxalement, une bonne traduction ne doit pas être pensée comme une interprétation. Parce que l'interprétation est de l'ordre du sens, et du signe. Du discontinu. Radicalment différent du texte, qui fait ce qu'il dit. Le texte est porteur et porte. L'interprétation, seulement portée. La bonne traduction doit faire, et non seulement dire. Elle doit, comme le texte, être porteuse et portée.

${ }^{4}$ Original: L'herméneutique appliquée à la traduction ne transporte qu'un cadavre. Ou plutôt son esprit. Le corps est resté sur l'autre rive. Et l'esprit seul est sans voix.
} 
Bastos, B. C. - O sentido e o som: três teorias da tradução de poesia em diálogo

No século 20, diz Meschonnic, o pensamento linguístico teria passado, pouco a pouco, de certa concepção de língua - com suas categorias lexicais, morfológicas e sintáticas - ao discurso, ao sujeito ativo, inscrito prosódica e ritmicamente na linguagem (p. 13). A tradução teria acompanhado esta mudança:

\begin{abstract}
Descobre-se que uma tradução de um texto literário deve fazer o que faz um texto literário, através de sua prosódia, seu ritmo, sua significância, como uma das formas de individuação, como uma formasujeito. O que desloca radicalmente os preceitos de transparência e fidelidade da teoria tradicional [...]. A equivalência buscada não se coloca mais de língua a língua, ao tentar fazer esquecer as diferenças linguísticas, culturais, históricas. Ela se coloca de texto a texto, e trabalha, ao contrário, no sentido de mostrar a alteridade linguística, cultural, histórica, como uma especificidade e uma historicidade. ${ }^{5}$ (MESCHONNIC 1999: 16).
\end{abstract}

0 que deve ser traduzido, portanto, é o discurso, a oralidade, a historicidade, o ritmo-sujeito, ou "a banalidade mesmo" (p. 12). Para Meschonnic, quanto mais o tradutor estiver inscrito como sujeito na tradução, mais esta dará continuidade ao texto. Um exemplo disso seriam as traduções de São Jerônimo, que não pretendiam ser transparentes; ao contrário, constituíam uma espécie de relação com o hebraico. A tradução não deve deixar que se apaguem todas as particularidades que pertencem a um outro modo de significar, não deve apagar as distâncias de tempo, de língua e de cultura (p. 26). Na teoria e na prática, a função da tradução é "forçar a reconhecer" a historicidade do poema, a sua diferença.

\footnotetext{
${ }^{5}$ Original: On découvre qu' une traduction d'un texte littéraire doit faire ce que fait un texte littéraire, par son prosodie, son rythme, sa signifiance, comme une des formes de l'individuation, comme une forme-sujet. Ce que déplace radicalement les préceptes de transparence et fidélité de la théorie traditionnelle [...]. L'équivalence recherchée ne se pose plus de langue à langue, en essayant de faire oublier les différences linguistiques, culturelles, historiques. Elle est posée de texte à texte, en travaillant au contraire à montrer l'altérité linguistique, culturelle, historique, comme une spécificité et une historicité.
} 
Bastos, B. C. - O sentido e o som: três teorias da tradução de poesia em diálogo

Meschonnic oferece vários exemplos de sua poética do traduzir. Apresentamos sua tradução para o francês de um poema chinês clássico. 0 poema é de Meng Ha-jan (689-740), um quarteto de versos de cinco caracteres, no qual cada caractere é uma palavra monossilábica (a forma clássica chinesa). Vejamos o poema em chinês, acompanhado de uma tradução "literal" para o francês e de outras duas traduções para o francês (essas, tiradas de antologias de poemas chineses):

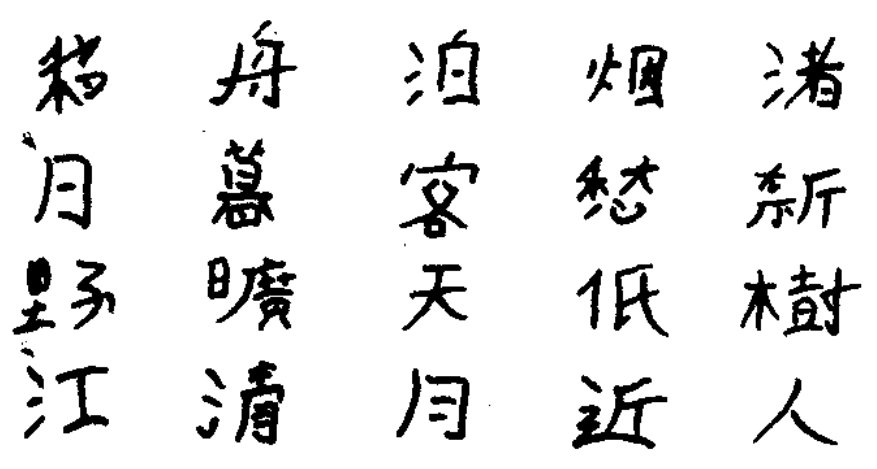

Tradução “literal” em francês:

Déplaçant barque/ accoster flot brumeux

Soleil couchant/ tristesse du voyager ravivée

Plaine immense/ ciel s'abaisser vers les arbres

Rivière limpide/ lune se rapprocher des hommes

(1999: 193)

Tradução de François Cheng:

Dans les brumes, prés de l'ile, on amarre le barque.

Au crépuscule renaît la tristesse du voyager.

Plaine immense: le ciel se penche sur les arbres.

Fleuve limpide: la lune s'approche des humains.

(1999: 193) 
Bastos, B. C. - O sentido e o som: três teorias da tradução de poesia em diálogo

Tradução de Patrick Carré e Zeno Bianu:

Prés de l'îlot de brume notre bateau s'arrête,

Au couchant qui ravive toute mélancolie.

Par cette immensité, le ciel verse sous les arbres.

Sur le fleuve pur, la lune rejoint l'homme.

(1999: 193)

Primeiramente, Meschonnic faz algumas ressalvas sobre as traduções apresentadas. Na primeira, de François Chen, haveria uma distorção da sintaxe dos verbos em chinês, pelo uso do particípio e de infinitivos, pois, lembra, não há formas conjugadas em chinês. Porém, o principal problema, tanto da tradução de Chen como da tradução de Carré e Bianu, seria que, de formas diferentes, elas mudam de lugar os grupos dos primeiros versos; e isso porque ambas querem se aproximar do alexandrino, como se assim fossem tornar o poema chinês mais poético, por aproximá-lo à tradição do "verso nacional" francês. O princípio poético do original teria desaparecido, ao ser trocado por outro. Assim, Meschonnic imagina um princípio poético que dê uma ideia, em francês, da métrica chinesa. Se as alternâncias de tons não podem ser transmitidas, a cesura e o monossilabismo podem. Para ultrapassar os limites linguísticos, ele diz, é suficiente adotar células de duas sílabas pronunciadas, e ater-se rigorosamente a esse princípio. Além disso, os brancos entre essas células tomam o lugar da pontuação, transmitindo melhor a indeterminação, o valor alusivo do poema chinês. Vejamos sua tradução:

vogue la barque aborde une île de brume
soleil couché le vague à l'âme voyage
la plaine est vaste le ciel est bas sur l'arbre
le fleuve est clair la lune est proche à l'homme
(1999: 194)


Bastos, B. C. - O sentido e o som: três teorias da tradução de poesia em diálogo

Mesmo se não lemos chinês, constatamos que, ao menos graficamente, pelo modo como as palavras estão dispostas, a tradução de Meschonnic é a única que se aproxima da visualidade do poema original e que não tenta fazer do poema chinês um alexandrino, ou seja, não tenta convertê-lo a uma forma que seja reconhecida como "poética" no francês. Ele permite que o estranho permaneça estranho e, consequentemente, permite que o poema chinês ganhe vida e corpo próprios na tradução.

\section{Transcriação}

México 5, D.F.

7 de maio de 1981

Caro Haroldo,

Obrigada por sua carta. Tenho pouquíssimo a comentar. Estou de acordo com tudo o que você me diz. Sua carta maravilhou-me, não só pela felicidade das soluções que você encontrou para cada problema, como também pela forma com que você explica a razão dessas soluções. Pouquíssimas vezes vi unidas, como no seu caso, sensibilidade auditiva e semântica. Ao lê-lo, voltei a comprovar que poesia é palavra dita e ouvida: uma atividade espiritual profundamente física na qual intervêm os lábios e a sonoridade. Atividade sensual, muscular, e espiritual. Por tudo isso, estou duplamente agradecido a você, por sua tradução e por suas luminosas explicações.

$[\ldots]$

(Carta de Octavio Paz a Haroldo de Campos, publicada no livro Transblanco.)

Octavio Paz escreveu essa carta a respeito da tradução para 0 português que Haroldo de Campos fez de seu poema "Blanco". Ele menciona aspectos que são, a nosso ver, centrais na prática e na teoria de Campos: a importância da sensibilidade auditiva e semântica, a visão da tradução como 
Bastos, B. C. - O sentido e o som: três teorias da tradução de poesia em diálogo

uma atividade "espiritual profundamente física", e a ênfase no aspecto sensual da tradução.

Diferentemente de Meschonnic, que enfatiza o modo de significar, Haroldo de Campos vai se concentrar na forma do poema, que ele descreve como "modo de intencionalidade". Grosso modo, podemos dizer que o que Meschonnic chama de ritmo, Campos chama de função poética, seguindo uma tradição mais formalista. o que importa é que tanto o ritmo, para Meschonnic, quanto a função poética, para Campos, têm uma função configuradora, servindo como uma espécie de partitura para a tradução.

Traduzir a forma, ou seja, o "modo de intencionalidade" (Art de Meinens) de uma obra - uma forma significante, portanto, intracódigo semiótico - quer dizer, em termos operacionais, de uma pragmática do traduzir, re-correr 0 percurso configurador da função poética, reconhecendo-o no texto de partida e reinscrevendo-o, enquanto dispositivo de engendramento textual, na língua do tradutor (CAMPOS 1981: 181).

Enquanto Meschonnic critica duramente a noção saussuriana de signo, Campos entende que a materialidade está incluída na totalidade do signo e que é exatamente essa totalidade que deve ser traduzida. Assim, parece-nos que também aqui eles falam de coisas parecidas. Ambos enfatizam a inutilidade da tradução de palavra por palavra, de sentido por sentido. Em "Da tradução como criação e crítica", de 1967, Campos afirma que a tradução poética deve transcender a preocupação de fidelidade ao significado, a fim de conquistar uma fidelidade ao signo estético "como entidade total, indiviso, na sua realidade material" (p. 35).

Então, para nós, tradução de textos criativos será sempre recriação, ou criação paralela, autônoma porém recíproca. Quanto mais inçado de dificuldades esse texto, mais recriável, mais sedutor enquanto possibilidade aberta de recriação. Numa tradução dessa natureza não se traduz apenas o significado, traduz-se o próprio signo, ou seja, sua fisicalidade, sua materialidade mesma [...]. O significado, o parâmetro 
Bastos, B. C. - O sentido e o som: três teorias da tradução de poesia em diálogo

semântico, será apenas e tão-somente a baliza demarcatória do lugar da empresa recriadora (CAMPOS 1967: 24).

Outro paralelo que pode-se estabelecer entre as teorias de tradução de Meschonnic e Campos diz respeito à implicação do suj eito no ato de traduzir. Eles recusam terminantemente 0 apagamento do tradutor, ou a ideia de tradução como atividade passiva, quando o tradutor almeja naturalidade e transparência no texto de chegada. Para ambos, a tradução deve ser uma relação entre a historicidade do tradutor e a historicidade do texto; não se devendo tentar apagar as diferenças de tempo e espaço. Partindo do princípio de que a poesia é intraduzível, Campos conclui que traduzir só é possível se for recriação, criação paralela, transcriação. Assim como o poema-texto é uma "informação estética autônoma", a tradução também deve sê-lo. Ou seja, apesar da diferença entre as línguas, original e tradução "cristalizar-seão dentro de um mesmo sistema" (1967: 24) através da tradução transcriadora.

Em um texto posterior, "Transluciferação mefistofáustica", de 1981, Campos critica, de um lado, as traduções mediadoras, as quais visariam apenas auxiliar a leitura do original, e, do outro, as traduções que ele chama de "medianas", "que guardariam da aspiração estética apenas as marcas externas de um dado esforço de versificação [...] e de um deliberado empenho rímico" (1981: 184). O que ele apregoa é a leitura partitural, uma leitura "verdadeiramente crítica". Ou seja, é preciso fazer uma leitura que seja "antes de tudo uma vivência interior do mundo e da técnica do traduzido" (1967: 31). É preciso fazer uma "vivissecção implacável", revolver as entranhas do poema. E não menos importante, diz Campos, é a atenção ao suporte físico, que deve muitas vezes tomar a dianteira nas preocupações do tradutor (Ibid.: 35).

A proposta de transcriação de Haroldo de Campos fazia parte do programa maior do concretismo e sua missão de reformular a poesia 
Bastos, B. C. - 0 sentido e o som: três teorias da tradução de poesia em diálogo

brasileira. Os concretistas, além das atividades teóricas e de criação poética, propunham uma "continuada tarefa de tradução" (Ibid.: 30). Herdeiros de Ezra Pound em sua concepção sobre a função da crítica ecoavam diretamente a prática poundiana de tradução. Haroldo de Campos chega a dizer que 0 ensino da literatura é inviável se não for colocado "o problema da amostragem e da crítica via tradução" (Ibid.: 34). Traduzir seria também um relacionar-se com a tradição:

\begin{abstract}
Um movimento tático de retorno, relendo o passado em modo sincrônico com ganas de reatualizá-lo, repristiná-lo, de fazer pessoanamente - do outrora, agora. De certo modo, isso é inevitável, pois se a tradução é uma leitura da tradição, só aquela ingênua e não crítica - que se confine ao museológico [...] recusar-se-á ao "salto tigrino" (W. BENJ AMIM) do sincrônico sobre o diacrônico (CAMPOS 1981: 188).
\end{abstract}

As traduções convencionais, em oposição à transcriação, correriam o risco de serem excessivamente acadêmicas ou conservadoras (o que remete àquelas tentativas dos tradutores franceses de fazer do poema clássico chinês um alexandrino francês). Por isso, seria importante esse tratamento sincrônico da tradição, pois, na tradução, como em uma paródia, além da voz do original, outras vozes textuais também se fazem ouvir. A tradução como forma de apropriação do "patrimônio literário extante"; como modo de capturar o "movimento plagiotrópico geral da literatura" (1981: 191).

Logo, enquanto Meschonnic diz que não se deve confundir métrica/forma com o que ele chama de ritmo, Campos afirma que não se pode confundir os aspectos mais óbvios e exteriores, como a métrica e 0 rimário, com a "complexa e sutil dinâmica da função poética, em sua multiplicidade configuradora" (Ibid.: 184). E Campos vai além: diz que apenas a leitura partitural, própria da tradução radicalmente criativa, pode ter acesso ao texto como um todo; e que o poeta-tradutor precisa ter um estoque 
Bastos, B. C. - O sentido e o som: três teorias da tradução de poesia em diálogo

"mobilizável" de formas significantes, do contrário não terá êxito na reconfiguração da "melhor poesia do passado" (Ibid.: 185).

Teoricamente, portanto, estão claras as exigências de tradução para esses teóricos: de um lado, a ênfase no ritmo, do outro, a ênfase no "signo total" e na tradução como recriação. Em ambos, a crítica ferrenha às tentativas de se reduzir a poesia à métrica ou às rimas ou de se reduzir a tradução a uma interpretação dos sentidos. No entanto, ao lermos as explicações que eles dão para as suas traduções, não deixamos de encontrar análises da métrica e das rimas, além de leituras microscópicas de todos os jogos semânticos, sintáticos, morfológicos e prosódicos presentes no original.

Haroldo de Campos coloca em prática sua teoria ao traduzir uma passagem do Fausto de Goethe, uma cena que é um breve diálogo entre o Grifo e Mefistófeles. Segundo Campos, Roman Jakobson já teria usado esta mesma cena para mostrar como "palavras ligadas por som e sentido manifestam 'afinidades eletivas', capazes de modificar a confirmação e 0 conteúdo das palavras envolvidas" (J AKOBSON e WAUGH apud CAMpos 1981: 181). É segundo esta perspectiva que Campos comenta e compara diferentes traduções.

Original alemão, de Goethe:

GREIF, schnarrend:

Nicht Greisen! Greifen! - Niemand hört es gern,

Dass man ihn Greis nemt. J edem Worte klingt

Der Ursprung nach, wo es sich her bedingt;

Grau, grämlich, griesgram, greulich, Gräber, grimmig,

Etymologisch gleicherweise stimmig

Verstimmen uns

MEPHISTOPHELES: Und doch, nicht abzuschweifen, Gefällt das Grei im Ehrentitel Greifen.

(1981: 181)

Tradução para o espanhol, de Rafael Cansinos Assens: 
Bastos, B. C. - O sentido e o som: três teorias da tradução de poesia em diálogo

GRIFO - (Chirriando) ¡Nada de ancianos! ¡Grifos! A nadie le hace gracia que lo llamen anciano. En cada palabra traslúcese el origen de donde procede; gris, canoso, caduco, sepulcros, feo, que suenam etimologicamente lo mismo, no resultam gratos a nuestros oídos.

MEFISTÓFELES - Y, sin embargo, para no divagar, lo de Grei no desagrada en el título honroso de grifos.

(1981: 181)

Tradução para o português de Agostinho D'Ornellas:

GRIFO (rosnando) Não são velhos, são Grifos! - Ninguém gosta

De ouvir chamar-se velho. Cada termo

Da origem donde vem tira o sentido:

Velho, vilão, velhaco, vil, velhote,

Sons na etimologia quase análogos,

Desagradam-nos muito.

MEFISTÓFELES Todavia,

Para não divagar, direi que "garras"

À ideia traz o título de Grifo.

(1981: 186)

Tradução para o português de J enny Klabin Segall:

GRIFO

(rosnando)

Grilos, não! Grifos! - ninguém quer que o chamem

De velho e Grilo! Inda que em todo o termo tina

0 som de base de que se chama origina

Grileira, grima, grife, gris, sangria,

Há concordância de etimologia,

Mas soam mal pra nós.

MEFISTÓFELES

Sons não tarifo

Mas vale o grif no honroso título de Grifo.

(1981: 187)

Destacaremos apenas alguns pontos especialmente importantes da análise de Campos dessas traduções. Certos aspectos do poema são 
Bastos, B. C. - 0 sentido e o som: três teorias da tradução de poesia em diálogo

suficientemente visuais - como a diagramação e a repetição de letras - e não é sequer preciso saber ler em alemão para percebê-los. Por exemplo, a tradução para o espanhol é feita em prosaicas linhas corridas, o que já sinaliza certa "traição" da forma do original. Além disso, diz Campos, o tradutor espanhol se absteve totalmente de tentar transpor certas dificuldades do texto (como as aliterações que ocorrem no alemão), preferindo usar notas para explicar estas dificuldades (p. 185). A tradução realizada por Ornellas, por sua vez, manteve os versos, a baliza métrica e tentou "restabelecer a cadeia aliterativa do texto goethiano, fulcrando-a em torno de "velho'"; porém, critica Campos, nada ficou do jogo de rimas do original (p. 186). A tradução de Segall seria mais bem-sucedida, pois lida com os diversos níveis do poema e procura manter a métrica e a rima. No entanto, certas rimas, como entre "tarifo" e "Grifo", seriam um tanto forçadas; e certas escolhas semânticas não seriam boas, como o termo "grima", em desuso (p. 187). Ou seja, conclui o autor, Segall parece ter percebido 0 "modo de intencionalidade" do original, mas não obteve sucesso em sua recriação.

Estes seriam exemplos de traduções comuns, "naturais" (p. 184). A tradução transcriativa, por sua vez, representaria um esforço de recriação. Para explicitar o funcionamento de sua tradução, Campos faz uma lista do "léxico chave" do original - todas as palavras iniciadas por "gr", como greis, greif e grimmig; explica os sentidos destas palavras; depois uma outra lista, em português, com palavras equivalentes. Ou não exatamente equivalentes, pois, como ele diz, tratar-se-ia de uma "reconstituição da ambiência fonosemântica" (p. 183). Campos mantém, além da sugestão semântica, aspectos fônicos das palavras, pois em português todos esses vocábulos também começam com "gr". E expõe detalhadamente o modo como sua tradução é capaz de recriar os efeitos aliterativos, os jogos de palavras, e a "força do contágio de significantes convergentes e coincidentes" (p. 182). Para Campos, a fala do Grifo evidenciaria, "ao nível mais imediato", o caráter 
Bastos, B. C. - O sentido e o som: três teorias da tradução de poesia em diálogo

autorreflexivo da função poética (p. 181). E sua transcriação, por sua vez, deseja dar conta desta reflexividade.

UM GRIFO, resmungando:

Gri não de gris, grisalho, mas de Grifo!

Do gris de giz, do grisalho de velho

Ninguém se agrada. 0 som é um espelho

Da origem da palavra, nela inscrito.

Grave, gralha, grasso, grosso, grés, gris

Concertam-se num étimo ou raiz

Rascante, que nos desconcerta.

MEFISTÓFELES: 0 Grifo

Tem grito e garra no seu nome-título.

(1981: 182)

\section{Avaliando traduções}

Meschonnic e Campos, apesar de críticos quanto à preocupação com "fidelidade" das traduções convencionais, ao se esforçarem por não deixar de lado a especificidade e a historicidade dos poemas que traduzem, parecem mais fiéis do que seria de se esperar. A tradução do poema clássico chinês realizada por Meschonnic é de algum modo mais "fiel" ao original do que as outras traduções. $E$ podemos dizer 0 mesmo sobre as traduções dos concretistas, ou seja, que, mesmo sendo transcriações, refletem tal preocupação com a forma e com o espírito do original que acabam sendo mais "fiéis" do que as traduções ditas convencionais.

Em "Augusto de Campos como tradutor", de 2004, Paulo Henriques Britto observa sobre as traduções de Hopkins feitas por Augusto de Campos: 
Bastos, B. C. - O sentido e o som: três teorias da tradução de poesia em diálogo

Se a linguagem poética é aquela que utiliza com o máximo de proveito os diferentes planos da fonética, morfossintaxe, semântica e prosódia, o que se pode exigir de uma tradução poética senão que ela reproduza o máximo de efeitos do poema original em todos estes planos? 0 que Augusto de Campos faz com o soneto de Hopkins pode ser chamado de transcriação, transhopkinsação ou qualquer outro nome que se lhe queira dar; mas é nada mais - nem nada menos - do que uma tradução esplêndida. A meu ver, ao contrário do que eles apregoam, Augusto e seus companheiros não inventaram nenhum processo novo e revolucionário no campo da tradução de poesia, e sim elevaram o nível de qualidade de seu ofício a um patamar raramente atingido antes (BRITTO 2004: 333).

Podemos aproveitar 0 gancho deste comentário para expor 0 pensamento deste outro poeta, tradutor e teórico da tradução de poesia. Sem querer ser revolucionária, a teoria da tradução de Paulo Henriques Britto tem o mérito de tornar mais próximo, mais analisável e mais objetivo o trabalho de tradução de poesia. (Embora falar de objetividade no terreno da poesia não deixe de ser uma ousadia.) O que Britto faz pode ser chamado em alguns momentos de "prosódia comparada", pois ele usa os termos língua-meta, língua de saída, correspondência, fidelidade. Como adverte Meschonnic, ao usar estes termos, corre-se o risco de encarar a tradução como mera interpretação, de produzir um texto que seja apenas "portador" (porteur), de perder o aspecto literário do texto. Porém, a nosso ver, a abordagem de Britto permite uma complexidade na leitura do poema que também é "partitural", que também vai acessar seu "modo de significar".

Em "Para uma avaliação mais objetiva das traduções de poesia", de 2002, Britto escreve:

Temos consciência de que o texto poético trabalha com a linguagem em todos os seus níveis - semânticos, sintáticos, fonéticos, rítmicos, entre outros. Idealmente, o poema deve articular todos esses níveis, ou pelo menos vários deles, no sentido de chegar a um determinado conjunto harmônico de efeitos poéticos. A tarefa do tradutor de poesia será, pois, a de recriar, utilizando os recursos da língua-meta, os efeitos de sentido e forma do original - ou, ao menos, uma boa parte deles (BRITTO 2002: 54). 
Bastos, B. C. - O sentido e o som: três teorias da tradução de poesia em diálogo

Ao analisar um poema, o tradutor deve se perguntar qual, entre todos os efeitos poéticos, se apresenta de forma mais regular ou mais constante no poema original. Os efeitos poéticos dizem respeito tanto à forma quanto ao aspecto semântico do poema. E como se trata de poesia, a complexidade vem do fato de que é impossível discernir nitidamente formas e sentidos.

Britto propõe que seja feita uma espécie de hierarquização dos diferentes efeitos poéticos. Olhando para a totalidade do poema, o tradutor deve discernir quais são suas características mais marcantes, e se concentrar nesses elementos ao traduzir. É com este aspecto do poema que o tradutor deve buscar um maior nível de correspondência. Por exemplo, em sua análise do poema "The shampoo", de Elizabeth Bishop, Britto afirma que a métrica deste poema não é rigorosa, mas o seu esquema de rimas é bastante regular. Sendo assim, mais do que com o número de sílabas, a tradução deve se ocupar das rimas (2002: 59). As "perdas" decorrem do fato de que nem todos os elementos do poema poderão ser traduzidos, mas o tradutor pode se considerar satisfeito se conseguir recriar os elementos mais importantes. Pode acontecer também que efeitos poéticos do original, como as aliterações - um recurso muito menos comum em português do que em inglês -, sejam deslocados para outro verso do poema, funcionando como uma espécie de compensação.

Seguindo Britto, podemos também pensar a relação entre tradução e texto original em termos de correspondência funcional ou formal. A tradução funcional é aquela mais preocupada com que a tradução funcione em um determinado contexto tradutório, em determinada língua. A tradução formal, ao contrário, é aquela que vai se apegar mais à forma, e o problema é que uma mesma forma pode ter conotações muito diferentes em diferentes línguas. Para que isso fique mais claro, vejamos o caso das traduções para 
Bastos, B. C. - O sentido e o som: três teorias da tradução de poesia em diálogo

poemas de Emily Dickinson discutidas por Britto no texto "Correspondência formal e funcional em tradução poética", de 2006.

\begin{abstract}
Em toda sua obra, Dickinson recorre às formas mais simples de que dispõe o repertório prosódico do inglês - as formas de balada - para por meio delas compor poemas de uma complexidade intelectual notável. Assim, o contraste entre a singeleza da forma e a densidade do sentido é um efeito importante de sua poesia. Isso nos leva ao seguinte problema: ao traduzir Dickinson, devemos nos ater à correspondência formal - i.e., tentar recriar formas análogas às do original com os recursos do português - ou devemos buscar uma correspondência funcional - procurar encontrar no nosso idioma recursos formais que tenham, no contexto poético lusófono, um significado análogo ao das formas utilizadas no original? (BRITTO 2006b: 57).
\end{abstract}

Faz parte da tradição incorporar formas estrangeiras ao repertório poético, afirma Britto. O soneto, o haiku, a sextina, são formas que vieram para o português de outras tradições poéticas e, portanto, é claro que a tradução formal produz enormes ganhos. Mas, em sua própria tradução de Dickinson, Britto opta por uma tradução funcional, isto é, ele usa a redondilha maior, que seria o correspondente, no contexto lusófono, da balada inglesa, trazendo suas conotações de simplicidade e folkiness. 0 fator complicador é que, dentro do uso da forma simples da balada, Dickinson faz inovações. Ela usa rimas consonantais que, segundo Britto, constituíram uma importante inovação na prosódia do inglês, posteriormente adotada por muitos poetas modernos. Em sua tradução, Britto usou rimas toantes para traduzir as rimas consonantais de Dickinson, e embora ocorra uma boa analogia formal entre estes dois tipos de rima, perde-se o caráter inovador do poema, pois em português as rimas toantes já fazem parte do repertório popular, não decorrem de uma escolha poética consciente.

Britto analisa as traduções de José Lira, que opta por uma tradução formal, importando para o português a rima consonantal. Isso seria coerente afinal, se houve inventividade na forma em inglês, deve haver também em 
Bastos, B. C. - O sentido e o som: três teorias da tradução de poesia em diálogo

português. 0 difícil, afirma o autor, é fazer com que a inventividade funcione. Ao seu ver, a transposição das rimas consonantais para o português não funciona. Elas não chegam sequer a ser percebidas como rimas, pois "a centralidade das tônicas na rima portuguesa é incontornável" (BRITTO 2006b: 62). Nesse caso, a tentativa de importar uma forma poética não teria obtido 0 efeito desejado.

Um último ponto das reflexões de Britto que gostaríamos de trazer está colocado mais explicitamente no artigo "Fidelidade em tradução poética: 0 caso Donne" (2006). Neste texto, Britto afirma a possibilidade de se avaliar traduções de poesia de modo minimamente objetivo. Mais diretamente, 0 autor está respondendo ao comentário de Rosemary Arrojo, quando esta diz: "a tradução de um poema e avaliação dessa tradução não poderão realizar-se fora de um ponto de vista ou de uma perspectiva, ou sem mediação de uma 'interpretação'." (ARRojo apud BRITTO 2006a: 239). Para Arrojo, como a tradução é inevitavelmente da ordem da leitura e da interpretação, o fato de considerarmos uma tradução superior a outra refletiria sobretudo uma afinidade maior entre os nossos pressupostos e os pressupostos de determinado tradutor; ou seja, preferimos uma tradução quando a nossa leitura "combina" mais com a leitura de um certo tradutor. Britto, por sua vez, não vê na instabilidade dos significados um impedimento para uma avaliação mais objetiva. Sem negar que toda e qualquer tradução vai se dar dentro de uma perspectiva, ele afirma a possibilidade de avaliar e comparar diferentes traduções.

É verdade que não temos acesso ao real e que todas nossas opiniões são qualificadas pelos nossos pressupostos, mas essa constatação não leva à conclusão de que todas as traduções, ou todas as teorias, são igualmente "legítimas e competentes". Pelo contrário, é precisamente porque não temos esse acesso direto ao real que é necessário analisar, discutir e tentar estabelecer consensos, ainda que parciais - pois se 0 real se oferecesse diretamente como evidência à inteligência humana, o que haveria para discutir? (BRITTO 2006a: 240-241). 
Bastos, B. C. - O sentido e o som: três teorias da tradução de poesia em diálogo

Britto procede então a análise e comparação das traduções de Augusto de Campos e de Paolo Vizioli para o poema "Going to bed", de J ohn Donne. Ele faz uma análise minuciosa das duas traduções, comparando-as ao original e avaliando, entre outros elementos, perdas semânticas, acréscimos de palavras, mudanças na sintaxe, rimas e associações fônicas. Desse modo, elabora um tipo de análise em que o cotejo das traduções com o original permite conclusões mais palpáveis do que apenas "esta tradução flui melhor", ou "esta tradução preserva o espírito do original". A nosso ver, ao tornar mais objetiva a comparação entre as traduções, assim como Meschonnic, Britto também vai contra o "império dos significados", colocando o sentido como um dentre os vários aspectos que deve ser traduzido. E em sua busca por certa objetividade, não deixa de estabelecer uma "erótica" da tradução.

\section{Considerações finais}

$\mathrm{Na}$ introdução, sugerimos que o trabalho de tradução poderia se oferecer como um espaço privilegiado para se pensar a poesia de acordo com os preceitos "contra-interpretativos" de Susan Sontag. Os três teóricos que trouxemos parecem formular, cada um ao seu modo, suas próprias "eróticas": enfatizando o ritmo, a materialidade, os diversos níveis de efeitos que compõem o poema e demonstrando como para traduzir é preciso fazer uma "descrição realmente cuidadosa, aguda, carinhosa" do poema. Assim, o aspecto semântico-interpretativo coloca-se como um dos momentos do trabalho tradutório; e a própria instabilidade dos sentidos, na medida em que é um dos efeitos da poesia, também deve ser incorporada ao texto traduzido. 
Bastos, B. C. - O sentido e o som: três teorias da tradução de poesia em diálogo

Um dos aspectos interessantes do trabalho de tradução é que ele parece necessariamente levar a este "corpo a corpo" com o texto. No entanto, nem a nossa leitura particular, tampouco o texto, são transparentes. 0 acesso ao texto vai sempre se dar através das ideias e da 'historicidade' de cada um. Mas é justamente não perdendo de vista essa complexidade que poderemos ler/ouvir/tocar melhor o poema, torná-lo mais real e, consequentemente, realizar traduções mais interessantes.

\section{Referências bibliográficas}

BedettI, G. Henri Meschonnic: Rhythm as Pure Historicity. New Literary History, 2002, vol 23. n.2, pp. 431-450.

BRITTO, P. H. Julho-dezembro, 2006a. Fidelidade em tradução poética: o caso Donne. Terceira Margem, v. 15, pp. 239-254.

. Correspondência formal e funcional em tradução poética in Sob o signo de Babel: literaturas e poéticas da tradução. Org. MARCelo PAIVA SouZA et AL. VITÓRIA, PPGL/ MEL, Flor\&Cultura, 2006b, pp. 1-15.

Augusto de Campos como tradutor in Sobre Augusto de Campos. Org. FloRA SÜSSEKIND E Júllo CASTAÑon GUIMARÃes. Rio de Janeiro, 7Letras/ Fundação Casa de Rui Barbosa, 2004, pp. 323-343.

- Para uma avaliação mais objetiva das traduções de poesia in As margens da tradução. Org. Gustavo BeRnARDo KRAUSE. Rio de Janeiro, FAPERJ / Caetés/ UERJ , 2002, pp. 54-67.

CAMPOS, H. de. Da tradução como criação e como crítica in Metalinguagem. Petrópolis, Vozes, 1967, pp. 21-38.

- Transluciferação mefistofaústica in Deus e o Diabo no Fausto de Goethe. São Paulo, Perspectiva, 1981, pp. 179- 209.

Campos, H. de e Paz, O. Transblanco. São Paulo, Siciliano, 1994.

MesCHONNIC, H. Poétique du traduire. Paris, Verdier, 1999. 
Bastos, B. C. - O sentido e o som: três teorias da tradução de poesia em diálogo

. La rime et la vie in La rime et la vie. Paris, Gallimard, 1989, pp. 247273.

SONTAG, S. Contra a interpretação in Contra a interpretação. Trad. de Ana Maria Capovilla. Porto Alegre, L\&PM, 1987, pp. 11-23. 